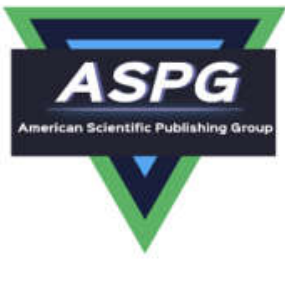

\title{
Neutrosophic Crisp Semi Separation Axioms In Neutrosophic Crisp Topological Spaces
}

\author{
Riad K. Al-Hamido ${ }^{1, *}$ Luai Salha ${ }^{2}$ Taleb Gharibah ${ }^{3}$ \\ ${ }^{1 *}$ Department of Mathematics, College of Science, AlFurat University, Deir-ez-Zor, Syria. \\ 1*E-mail: riad-hamido1983@hotmail.com; Tel.: (+963988619783) \\ ${ }^{2,3}$ Department of Mathematics, College of Science, AlBaath University, Homs, Syria.
}

\begin{abstract}
The main goal of this paper is to propose a new type of separation axioms via neutrosophic crisp semi open sets and neutrosophic crisp points in neutrosophic crisp topological spaces, namely neutrosophic crisp semi separation axioms. Finally, we examine the relationship between them in details. And also includes the study of the connections between these neutrosophic crisp semi separation axioms and the existing neutrosophic crisp separation axioms. Moreover, many examples are presented, to illustrate the concepts introduced in this paper. and investigate their fundamental properties, relationships and characterizations.
\end{abstract}

Keywords: Neutrosophic crisp semi separation axiom, neutrosophic crisp separation axiom, neutrosophic crisp point.

\section{Introduction}

After F.Samarandache established the concept of neutrosophy in 1980 the neutrosophy in 1980 as a new logic which generalizes the fuzzy logic, many of the pure mathematical concepts, especially in topology, were found according to this new logic. One of the most important topological developments according to this logic is finding out and defining the neutrosophic crisp topological space [1] in 2014 by A. Salama and et al. Since the elements of the neutrosophic crisp sets[1] are neutrosophic crisp points, A. Salama defined the concept of neutrosophic crisp points [1,2] in 2014. Recently, the neutrosophic crisp set theory may have applications in image processing [3],[4], the field of geographic information systems[5] and possible applications to database[6]. Also, neutrosophic sets [7] have applications in the medical field [8], [9], [10], [11]. We can't use neutrosophic crisp points were defined in [1,2] for defining the neutrosophic crisp separation axioms and this encouraged A. Al-nafey, R. Al-Hamido and F. Smarandache to think of presenting another new concept of the neutrosophic crisp points [12] in 2018, which enabled them to define separation axioms in the neutrosophic crisp space for the first time in [12] . Moreover, neutrosophic crisp semi open sets were first defined and investigated by A. Salama [5 ] in 2015. Since the separation

DOI: $10.5281 /$ zenodo.3831081 
axioms are considered one of the very important useful topics and one of the newly studied in topology, we thought of developing and generalizing the neutrosophic crisp separation axioms to neutrosophic crisp semi separation axioms. Finally, we study the relations between them on the one hand and between the separation neutrosophic crisps in [12] on the other hand. Many researchers studied topology, and they had many contributions to neutrosophic toplogy as [13], [14], [15], [16] and [17] and in neutrosophic bitopology in [18], [19], [20] and [21], and in neutrosophic algebra in [22], [23], [24], [25] and [26].

In this paper, Section 2 focuses on the related definitions. Section 3 presents new separation axioms in the neutrosophic crisp topological spaces, the relationship among these new separation axioms and the neutrosophic crisp separation axioms is determined.

\section{Preliminaries}

Throughout the paper, $(\chi, \mathrm{T})$ means neutrosophic crisp topological space $\left(\mathrm{N}_{\mathrm{c}} \mathrm{TS}\right)$.

$\mathrm{N}_{\mathrm{c}}$. OS $\left(\mathrm{N}_{\mathrm{c}}\right.$. CS) means a neutrosophic crisp open(closed) sets and $\mathrm{N}_{\mathrm{c}} \mathrm{S}$. OS means a neutrosophic crisp semi open set in $\mathrm{N}_{\mathrm{c}} \mathrm{TS}$.

Now, we recall some definitions which are useful in this paper.

Definition 2.1. [1] Let $X \neq \emptyset$ be a fixed set. A neutrosophic crisp set $\left(\mathrm{N}_{\mathrm{c}}\right.$. S) $U$ is an object with the $U=<U_{1}, U_{2}$, $U_{3}>$ shape ; $U_{1}, U_{2}$ and $U_{3}$ are subsets of $\mathrm{X}$.

\section{Definition 2.2. [1]}

$\emptyset_{\mathrm{N}}$ can be defined in four ways, as below :
1. $\varnothing_{N}=<\varnothing, \varnothing, \varnothing>$.
2. $\varnothing_{N}^{N}=<\varnothing, X, \varnothing>$.
3. $\varnothing_{N}^{N}=<\varnothing, X, X>$.
4. $\varnothing_{N}^{N}=<\varnothing, \varnothing, \varnothing>$.

$X_{\mathrm{N}}$ can be defined in four ways, as below :
1. $X_{N}=<X, \varnothing, \varnothing>$.
2. $X_{N}^{N}=<X, X, \varnothing>$.
3. $\varnothing_{N}^{N}=<X, \varnothing, X>$.
4. $X_{N}^{N}=<X, X, \quad X>$.

Definition 2.3. [1]

Let $\chi \neq \varnothing$ be a fixed set, and $\mathrm{U}=<U_{1}, U_{2}, U_{3}>, \mathrm{V}=<V_{1}, V_{2}, V_{3}>$ are two neutrosophic crisp sets, then:

$U \cup V$ can be defined as two ways, as below :

1. $U \cup V=<U_{1} \cup V_{1}, U_{2} \cup V_{2}, U_{3} \cap V_{3}>$.

2. $U \cup V=<U_{1} \cup V_{1}, U_{2} \cap V_{2}, U_{3} \cap V_{3}>$.

$U \cap V$ can be defined as two ways, as below :

1. $U \cap V=<U_{1} \cap V_{1}, U_{2} \cap V_{2}, U_{3} \cup V_{3}>$.

2. $U \cap V=<U_{1} \cap V_{1}, U_{2} \cup V_{2}, U_{3} \cup V_{3}>$.

Definition 2.4. [1]

A neutrosophic crisp topology (NCT) on a non-empty set $\chi$ is a family T of neutrosophic crisp subsets in $\chi$ may be satisying the following axioms:

1. $\mathrm{X}_{\mathrm{N}}$ and $\varnothing_{\mathrm{N}}$ belong to $\mathrm{T}$. 
2. $\mathrm{T}$ is closed under finite intersection.

3. $\mathrm{T}$ is closed under arbitrary union.

The pair $(\chi, \mathrm{T})$ is neutrosophic crisp topological space (NCTS) in T. Moreover, the elements in T are said to be neutrosophic crisp open sets (NCOS). A neutrosophic crisp set F is closed (NCCS) if and only if its complement $\mathrm{F}^{\mathrm{c}}$ is neutrosophic crisp open set.

\section{Definition 2.5. [12]}

Let $\chi$ be a non-empty set. And $\mathrm{x}, \mathrm{y}, \mathrm{z} \in \chi$, then:

a. $\mathrm{X}_{\mathrm{N}_{1}}=<\{\mathrm{x}\}, \emptyset, \varnothing>$ is called a neutrosophic crisp point $\left(\mathrm{NCP}_{\mathrm{N}_{1}}\right)$ in $\chi$.

b. $\mathrm{y}_{\mathrm{N}_{2}}=<\varnothing,\{\mathrm{y}\}, \emptyset>$ is called a neutrosophic crisp point $\left(\mathrm{NCP}_{\mathrm{N}_{2}}\right)$ in $\chi$.

c. $\mathrm{z}_{\mathrm{N}_{3}}=<\emptyset, \emptyset,\{\mathrm{z}\}>$ is called a neutrosophic crisp point $\left(\mathrm{NCP}_{\mathrm{N}_{3}}\right)$ in $\chi$.

The set of all neutrosophic crisp points $\left(\mathrm{NCP}_{\mathrm{N}_{1}}, \mathrm{NCP}_{\mathrm{N}_{2}}, \mathrm{NCP}_{\mathrm{N}_{3}}\right)$ is denoted by $\mathrm{NCP}_{\mathrm{N}}$.

\section{Definition 2.6. [12]}

Let $(\chi, \mathrm{T})$ be an $\mathrm{N}_{\mathrm{c}} \mathrm{TS}$. Then $\chi$ is called:

a. $\mathrm{N}_{1} \mathrm{~T}_{\mathrm{o}}$-space if for every $\mathrm{x}_{\mathrm{N}_{1}} \neq \mathrm{y}_{\mathrm{N}_{1}} \in \chi$ there exists $\mathrm{N}_{\mathrm{c}}$. OS $\mathrm{M}$ in $\chi$ containing one of them but not the other.

b. $\mathrm{N}_{2} \mathrm{~T}_{\mathrm{o}}$-space if $\forall \mathrm{x}_{\mathrm{N}_{2}} \neq \mathrm{y}_{\mathrm{N}_{2}} \in \mathcal{X}$ there exists $\mathrm{N}_{\mathrm{c}}$. OS $\mathrm{M}$ in $\chi$ containing one of them but not the other.

c. $\mathrm{N}_{3} \mathrm{~T}_{\mathrm{o}}$-space if $\forall \mathrm{x}_{\mathrm{N}_{3}} \neq \mathrm{y}_{\mathrm{N}_{3}} \in \chi$ there exists $\mathrm{N}_{\mathrm{c}}$. OS $\mathrm{M}$ in $\chi$ containing one of them but not the other.

d. $\mathrm{N}_{1} \mathrm{~T}_{1}$-space if for every $\mathrm{x}_{\mathrm{N}_{1}} \neq \mathrm{y}_{\mathrm{N}_{1}} \in \chi$ there exists $\mathrm{N}_{\mathrm{c}}$. OS $\mathrm{M}_{1}, \mathrm{M}_{2}$ in $\chi$ such that $\mathrm{x}_{\mathrm{N}_{1}} \in \mathrm{M}_{1}, \mathrm{y}_{\mathrm{N}_{1}} \notin \mathrm{M}_{1}$ and $\mathrm{x}_{\mathrm{N}_{1}} \notin$ $\mathrm{M}_{2}, \mathrm{y}_{\mathrm{N}_{1}} \in \mathrm{M}_{2}$

e. $\mathrm{N}_{2} \mathrm{~T}_{1}$-space if $\forall \mathrm{x}_{\mathrm{N}_{2}} \neq \mathrm{y}_{\mathrm{N}_{2}} \in \chi$ there exist $\mathrm{N}_{\mathrm{c}}$.OS $\mathrm{M}_{1}, \mathrm{M}_{2}$ in $\chi$ such that $\mathrm{x}_{\mathrm{N}_{2}} \in \mathrm{G}_{1}, \mathrm{y}_{\mathrm{N}_{2}} \notin \mathrm{G}_{1}$ and $\mathrm{x}_{\mathrm{N}_{2}} \notin \mathrm{G}_{2}, \mathrm{y}_{\mathrm{N}_{2}} \in$ $\mathrm{G}_{2}$.

f. $\quad \mathrm{N}_{3} T_{1}$-space if $\forall \mathrm{x}_{\mathrm{N}_{3}} \neq \mathrm{y}_{\mathrm{N}_{3}} \in \chi$ there exist $\mathrm{N}_{\mathrm{c}}$. OS $\mathrm{M}_{1}, \mathrm{M}_{2}$ in $\chi$ such that $\mathrm{x}_{\mathrm{N}_{3}} \in \mathrm{M}_{1}, \mathrm{y}_{\mathrm{N}_{3}} \notin \mathrm{M}_{1}$ and $\mathrm{x}_{\mathrm{N}_{3}} \notin \mathrm{M}_{2}, \mathrm{y}_{\mathrm{N}_{3}} \in$ $\mathrm{M}_{2}$.

g. $\mathrm{N}_{1} \mathrm{~T}_{2}$-space if for every $\mathrm{x}_{\mathrm{N}_{3}} \neq \mathrm{y}_{\mathrm{N}_{3}} \in \chi$ there exist $\mathrm{N}_{\mathrm{c}}$. OS $\mathrm{M}_{1}, \mathrm{M}_{2}$ in $\chi$ such that $\mathrm{x}_{\mathrm{N}_{1}} \in \mathrm{M}_{1}, \mathrm{y}_{\mathrm{N}_{1}} \notin \mathrm{M}_{1}$ and $\mathrm{x}_{\mathrm{N}_{1}} \notin \mathrm{M}_{2}$ , $\mathrm{y}_{\mathrm{N}_{1}} \in \mathrm{M}_{2}$. with $\mathrm{M}_{1} \cap \mathrm{M}_{2}=\emptyset$.

h. $\quad \mathrm{N}_{2} \mathrm{~T}_{2}$-space if $\forall \mathrm{x}_{\mathrm{N}_{2}} \neq \mathrm{y}_{\mathrm{N}_{2}} \in \chi$ there exist $\mathrm{N}_{\mathrm{c}}$. OS $\mathrm{M}_{1}, \mathrm{M}_{2}$ in $\chi$ such that $\mathrm{x}_{\mathrm{N}_{2}} \in \mathrm{M}_{1}, \mathrm{y}_{\mathrm{N}_{2}} \notin \mathrm{M}_{1}$ and $\mathrm{x}_{\mathrm{N}_{2}} \notin \mathrm{M}_{2}, \mathrm{y}_{\mathrm{N}_{2}}$ $\in \mathrm{M}_{2}$ with $\mathrm{M}_{1} \cap \mathrm{M}_{2}=\emptyset$.

i. $\quad \mathrm{N}_{3} \mathrm{~T}_{2}$-space if $\forall \mathrm{x}_{\mathrm{N}_{3}} \neq \mathrm{y}_{\mathrm{N}_{3}} \in \chi$ there exist $\mathrm{N}_{\mathrm{c}}$. OS $\mathrm{M}_{1}, \mathrm{M}_{2}$ in $\chi$ such that $\mathrm{x}_{\mathrm{N}_{3}} \in \mathrm{M}_{1}, \mathrm{y}_{\mathrm{N}_{3}} \notin \mathrm{M}_{1}$ and $\mathrm{x}_{\mathrm{N}_{3}} \notin \mathrm{M}_{2}, \mathrm{y}_{\mathrm{N}_{3}} \in$ $M_{2}$ with $M_{1} \cap M_{2}=\emptyset$.

\section{Separation axioms in a neutrosophic crisp topological space}

\section{Definition 3.1.}

Let $(\chi, T)$ be an NcTS. Then $\chi$ is called:

a. $N_{1}$ semiTo-space if for every $x_{N_{1}} \neq y_{N_{1}} \in \chi$ there exists NcS.OS M in $\chi$ containing one of them but not the other.

b. $\mathrm{N}_{2}$ semiTo-space if $\forall \mathrm{x}_{\mathrm{N}_{2}} \neq \mathrm{y}_{\mathrm{N}_{2}} \in \mathcal{X}$ there exists NcS.OS $\mathrm{M}$ in $\chi$ containing one of them but not the other.

c. $\mathrm{N}_{3}$ semiTo-space if $\forall \mathrm{x}_{\mathrm{N}_{3}} \neq \mathrm{y}_{\mathrm{N}_{3}} \in \chi$ there exists NcS.OS $\mathrm{M}$ in $\chi$ containing one of them but not the other.

\section{Definition 3.2.}

Let $(\chi, T)$ be an $\mathrm{N}_{\mathrm{c}}$ TS. Then $\chi$ is called:

a. $\quad \mathrm{N}_{1}$ semiT $T_{1}$-space if for every $\mathrm{x}_{\mathrm{N}_{1}} \neq \mathrm{y}_{\mathrm{N}_{1}} \in \chi$ there exist $\mathrm{N}_{\mathrm{c}} \mathrm{S}$.OS $\mathrm{M}_{1}, \mathrm{M}_{2}$ in $\chi$ such that $\mathrm{x}_{\mathrm{N}_{1}} \in \mathrm{M}_{1}, \mathrm{y}_{\mathrm{N}_{1}} \notin \mathrm{M}_{1}$ and $\mathrm{x}_{\mathrm{N}_{1}}$ $\notin \mathrm{M}_{2}, \mathrm{y}_{\mathrm{N}_{1}} \in \mathrm{M}_{2}$.

b. $\mathrm{N}_{2}$ semiT $T_{1}$-space if $\forall \mathrm{x}_{\mathrm{N}_{2}} \neq \mathrm{y}_{\mathrm{N}_{2}} \in \chi$ there exist $\mathrm{N}_{\mathrm{c}}$ S.OS $\mathrm{M}_{1}, \mathrm{M}_{2}$ in $\chi$ such that $\mathrm{x}_{\mathrm{N}_{2}} \in \mathrm{G}_{1}, \mathrm{y}_{\mathrm{N}_{2}} \notin \mathrm{G}_{1}$ and $\mathrm{x}_{\mathrm{N}_{2}} \notin \mathrm{G}_{2}$, $\mathrm{y}_{\mathrm{N}_{2}} \in \mathrm{G}_{2}$

c. $\quad \mathrm{N}_{3}$ semiT $T_{1}$-space if $\forall \mathrm{x}_{\mathrm{N}_{3}} \neq \mathrm{y}_{\mathrm{N}_{3}} \in \chi$ there exist $\mathrm{N}_{\mathrm{c}}$ S.OS $\mathrm{M}_{1}, \mathrm{M}_{2}$ in $\chi$ such that $\mathrm{x}_{\mathrm{N}_{3}} \in \mathrm{M}_{1}, \mathrm{y}_{\mathrm{N}_{3}} \notin \mathrm{M}_{1}$ and $\mathrm{x}_{\mathrm{N}_{3}} \notin \mathrm{M}_{2}$, $\mathrm{y}_{\mathrm{N}_{3}} \in \mathrm{M}_{2}$

\section{Definition 3.3.}

Let $(\chi, T)$ be an $\mathrm{N}_{\mathrm{c}} \mathrm{TS}$. Then $\chi$ is called:

a. $\mathrm{N}_{1}$ semiT $\mathrm{T}_{2}$-space if for every $\mathrm{x}_{\mathrm{N}_{1}} \neq \mathrm{y}_{\mathrm{N}_{1}} \in \chi$ there exists $\mathrm{N}_{\mathrm{c}} \mathrm{S}$.OS $\mathrm{M}_{1}, \mathrm{M}_{2}$ in $\chi$ such that $\mathrm{x}_{\mathrm{N}_{1}} \in \mathrm{M}_{1}, \mathrm{y}_{\mathrm{N}_{1}} \notin \mathrm{M}_{1}$ and $\mathrm{x}_{\mathrm{N}_{1}} \notin \mathrm{M}_{2}, \mathrm{y}_{\mathrm{N}_{1}} \in \mathrm{M}_{2}$. with $\mathrm{M}_{1} \cap \mathrm{M}_{2}=\varnothing$. 
b. $\quad \mathrm{N}_{2}$ semiT 2 -space if $\forall \mathrm{x}_{\mathrm{N}_{2}} \neq \mathrm{y}_{\mathrm{N}_{2}} \in \chi$ there exists $\mathrm{N}_{\mathrm{c}}$ S.OS $\mathrm{M}_{1}, \mathrm{M}_{2}$ in $\chi$ such that $\mathrm{x}_{\mathrm{N}_{2}} \in \mathrm{M}_{1}, \mathrm{y}_{\mathrm{N}_{2}} \notin \mathrm{M}_{1}$ and $\mathrm{x}_{\mathrm{N}_{2}} \notin \mathrm{M}_{2}$ , $\mathrm{y}_{\mathrm{N}_{2}} \in \mathrm{M}_{2}$ with $\mathrm{M}_{1} \cap \mathrm{M}_{2}=\emptyset$.

c. $\quad \mathrm{N}_{3}$ semiT 2 -space if $\forall \mathrm{x}_{\mathrm{N}_{3}} \neq \mathrm{y}_{\mathrm{N}_{3}} \in \chi$ there exists $\mathrm{N}_{\mathrm{c}}$ S.OS $\mathrm{M}_{1}, \mathrm{M}_{2}$ in $\chi$ such that $\mathrm{x}_{\mathrm{N}_{3}} \in \mathrm{M}_{1}, \mathrm{y}_{\mathrm{N}_{3}} \notin \mathrm{M}_{1}$ and $\mathrm{x}_{\mathrm{N}_{3}} \notin$ $\mathrm{M}_{2}, \mathrm{y}_{\mathrm{N}_{3}} \in \mathrm{M}_{2}$ with $\mathrm{M}_{1} \cap \mathrm{M}_{2}=\emptyset$.

\section{Theorem 3.4.}

Let $(\chi, \mathrm{T})$ be an $\mathrm{N}_{\mathrm{c}} \mathrm{TS}$, then :

1. Every $\mathrm{N}_{1} \mathrm{~T}_{0}$-space is $\mathrm{N}_{1}$ semi $\mathrm{T}_{0}$-space.

2. Every $\mathrm{N}_{2} \mathrm{~T}_{0}$-space is $\mathrm{N}_{2}$ semi $\mathrm{T}_{0}$-space.

3. Every $\mathrm{N}_{3} \mathrm{~T}_{0}$-space is $\mathrm{N}_{3}$ semi $\mathrm{T}_{0}$-space.

\section{Proof:}

1. Suppose that $(\chi, T)$ is an $N_{1} T_{0}$-space, therefore for every two $x_{N_{1}} \neq y_{N_{1}}$, there exists an $N_{c}$. OS $M$ in $\chi$ containing one of them to which the other does not belong. So there exists an $\mathrm{N}_{\mathrm{c}} \mathrm{S}$.OS $\mathrm{M}$ in $\chi$ containing one of them to which the other does not belong, therefore $\mathrm{X}$ is $\mathrm{N}_{1}$ semiT $_{0}$-space.

2. Similar to Proof 1 .

3. Similar to Proof 1.

\section{Remark 3.5.}

The converse of theorem 3.4 is not true, as it is shown in the following examples.

\section{Example 3.6.}

Let $\chi=\{a, b, c\}, \mathrm{T}=\left\{\varnothing_{N}, X_{N}, A\right\}, A=\{<\{a\}, \emptyset, \emptyset>\}$.

$N_{c} S . O S=\mathrm{T} \cup\{C=\{<\{a, b\}, \emptyset, \emptyset>\}, B=\{<\{a, c\}, \emptyset, \emptyset\rangle\}$.

Let $\mathrm{x}_{\mathrm{N}_{1}}=\{<\{b\}, \emptyset, \emptyset>\} \neq \mathrm{y}_{\mathrm{N}_{1}}=\{<\{c\}, \emptyset, \emptyset>\} \in \chi$ there is no a $\mathrm{N}_{\mathrm{c}}$.OS $\mathrm{M}$ in $\chi$ containing one of them but not the other. Therefore $(\chi, \mathrm{T})$ is not $\mathrm{N}_{1} \mathrm{~T}_{0}$-space.

Then $(\chi, T) \mathrm{N}_{1}$ semi $\mathrm{T}_{0}$-space, But $(\chi, \mathrm{T})$ is not $\mathrm{N}_{1} \mathrm{~T}_{0}$-space.

\section{Example 3.7.}

Let $\chi=\{a, b, c\}, \mathrm{T}=\left\{\emptyset_{N}, X_{N}, A\right\}, A=\{<\emptyset,\{a\}, \emptyset>\}$.

$N_{c} S . O S=\mathrm{T} \cup\{C=\{<\emptyset,\{a, b\}, \emptyset>\}, B=\{<\varnothing,\{a, c\}, \emptyset>\}$.

Let $\left.\mathrm{x}_{\mathrm{N}_{2}}=\{<\emptyset,\{b\}, \emptyset\rangle\right\} \neq \mathrm{y}_{\mathrm{N}_{2}}=\{\langle\emptyset,\{c\}, \emptyset\rangle\} \in \chi$ there is no a $\mathrm{N}_{\mathrm{c}}$.OS $\mathrm{M}$ in $\chi$ containing one of them but not the other. Therefore $(\chi, T)$ is not $\mathrm{N}_{2} \mathrm{~T}_{0}$-space.

Then $(\chi, T) \mathrm{N}_{2}$ semi $\mathrm{T}_{0}$-space, But $(\chi, \mathrm{T})$ is not $\mathrm{N}_{2} \mathrm{~T}_{0}$-space.

\section{Example 3.8.}

Let $\chi=\{a, b, c\}, \mathrm{T}=\left\{\emptyset_{N}, X_{N}, A\right\}, A=\{<\emptyset,\{a\}, \emptyset>\}$.

$N_{c} S . O S=\mathrm{T} \cup\{C=\{<\emptyset, \emptyset,\{a, b\}>\}, B=\{<\emptyset, \emptyset,\{a, c\},>\}$.

Let $\left.\left.\mathrm{x}_{\mathrm{N}_{3}}=\{<\emptyset, \emptyset,\{b\}\rangle\right\} \neq \mathrm{y}_{\mathrm{N}_{3}}=\{<\emptyset, \emptyset,\{c\}\rangle\right\} \in \chi$ there is no a $\mathrm{N}_{\mathrm{c}}$.OS $\mathrm{M}$ in $\chi$ containing one of them but not the other. Therefore $(\chi, T)$ is not $N_{3} T_{0}$-space.

Then $(\chi, T) \mathrm{N}_{3}$ semi $\mathrm{T}_{0}$-space, But $(\chi, \mathrm{T})$ is not $\mathrm{N}_{3} \mathrm{~T}_{0}$-space.

\section{Theorem 3.9.}

Let $(\chi, \mathrm{T})$ be an $\mathrm{N}_{\mathrm{c}} \mathrm{TS}$, then :

1. Every $N_{1} T_{1}$-space is $N_{1}$ semi $T_{1}$-space.

2. Every $N_{2} T_{1}$-space is $N_{2}$ semi $T_{1}$-space.

3. Every $\mathrm{N}_{3} \mathrm{~T}_{1}$-space is $\mathrm{N}_{3}$ semi $\mathrm{T}_{1}$-space.

\section{Proof:}

1. Suppose that $(\chi, T)$ is an $N_{1} T_{1}$-space, therefore for every two $x_{N_{1}} \neq y_{N_{1}}$, there exist an $N_{c}$.OS $M_{1}, M_{2}$ in $\chi$ such that $x_{N_{1}} \in M_{1}, y_{N_{1}} \notin M_{1}$ and $x_{N_{1}} \notin M_{2}, y_{N_{1}} \in M_{2}$. So there exists an $N_{c} S . O S M_{1}, M_{2}$ in $\chi$ such that $\mathrm{x}_{\mathrm{N}_{1}} \in \mathrm{M}_{1}, \mathrm{y}_{\mathrm{N}_{1}} \notin \mathrm{M}_{1}$ and $\mathrm{x}_{\mathrm{N}_{1}} \notin \mathrm{M}_{2}, \mathrm{y}_{\mathrm{N}_{1}} \in \mathrm{M}_{2}$.

Therefore $\mathrm{X}$ is $\mathrm{N}_{1}$ semiT $_{1}$-space.

2. Similar to Proof 1 .

3. Similar to Proof 1 .

\section{Remark 3.10.}

The converse of a theorem 3.9 is not true, as it is shown in the following example.

\section{Example 3.11.}

Let $\left.\chi=\{a, b, c\}, \mathrm{T}=\left\{\varnothing_{N}, X_{N}, A, B, C\right\}, A=\{<\{a\}, \emptyset, \emptyset>\}, B=\{<\{b\}, \emptyset, \emptyset>\}, C=\{<\{a, b\}, \emptyset, \emptyset\rangle\right\}$. 
$N_{c} S . O S=\mathrm{T} \cup\{G=\{<\{a, c\}, \emptyset, \emptyset>\}, H=\{<\{b, c\}, \emptyset, \emptyset>\}$.

Let $\mathrm{x}_{\mathrm{N}_{1}}=\left\{\langle\{b\}, \emptyset, \emptyset>\} \neq \mathrm{y}_{\mathrm{N}_{1}}=\left\{\langle\{c\}, \emptyset, \emptyset>\} \in \chi\right.\right.$ there is no $\mathrm{N}_{\mathrm{c}}$.OS $\mathrm{M}_{1}, \mathrm{M}_{2}$ in $\chi$ such that $\mathrm{x}_{\mathrm{N}_{1}} \in \mathrm{M}_{1}, \mathrm{y}_{\mathrm{N}_{1}} \notin \mathrm{M}_{1}$ and $\mathrm{x}_{\mathrm{N}_{1}} \notin \mathrm{M}_{2}, \mathrm{y}_{\mathrm{N}_{1}} \in \mathrm{M}_{2}$. Therefore $(\chi, T)$ is not $\mathrm{N}_{1} \mathrm{~T}_{1}$-space.

Then $(\chi, T) N_{1}$ semi $T_{1}$-space, But $(\chi, T)$ is not $N_{1} T_{1}$-space.

Also $(\chi, T) N_{1}$ semi $T_{2}$-space, But $(\chi, T)$ is not $N_{1} T_{2}$-space.

\section{Example 3.12.}

Let $\chi=\{a, b, c\}, T=\left\{\emptyset_{N}, X_{N}, A, B, C\right\}, A=\{<\varnothing,\{a\}, \emptyset>\}, B=\{\langle\emptyset,\{b\}, \emptyset>\}, C=\{\langle\emptyset,\{a, b\}, \emptyset>\}$.

$N_{c} S . O S=\mathrm{T} \cup\{G=\{\langle\varnothing,\{a, c\}, \emptyset>\}, H=\{<\varnothing,\{b, c\}, \emptyset>\}$.

Let $\mathrm{x}_{\mathrm{N}_{1}}=\{<\varnothing,\{b\}, \emptyset>\} \neq \mathrm{y}_{\mathrm{N}_{1}}=\{\varnothing,<\{c\}, \emptyset>\} \in \chi$ there are no a $\mathrm{N}_{\mathrm{c}} . \mathrm{OS} \mathrm{M}_{1}, \mathrm{M}_{2}$ in $\chi$ such that $\mathrm{x}_{\mathrm{N}_{2}} \in \mathrm{M}_{1}, \mathrm{y}_{\mathrm{N}_{2}} \notin$ $M_{1}$ and $x_{N_{2}} \notin M_{2}, y_{N_{2}} \in M_{2}$. Therefore $(\chi, T)$ is not $N_{2} T_{1}$-space.

Then $(\chi, T) N_{2}$ semi $T_{1}$-space, But $(\chi, T)$ is not $N_{2} T_{1}$-space.

Also $(\chi, T) \mathrm{N}_{2}$ semi T $_{2}$-space, But $(\chi, T)$ is not $\mathrm{N}_{2} \mathrm{~T}_{2}$-space.

\section{Example 3.13.}

Let $\chi=\{a, b, c\}, \mathrm{T}=\left\{\emptyset_{N}, X_{N}, A, B, C\right\}, A=\{\langle\emptyset, \emptyset,\{a\}>\}, B=\{\langle\emptyset, \emptyset,\{b\}>\}, C=\{\langle\emptyset, \emptyset,\{a, b\}\rangle\}$. $N_{c} S . O S=\mathrm{T} \cup\{G=\{<\varnothing, \emptyset,\{a, c\}>\}, H=\{\langle\emptyset, \emptyset,\{b, c\}\rangle\}$.

Let $\left.\mathrm{x}_{\mathrm{N}_{3}}=\{<\varnothing, \emptyset,\{b\}>\} \neq \mathrm{y}_{\mathrm{N}_{3}}=\{<\emptyset, \emptyset,\{c\}\rangle\right\} \in \chi$ there are no $\mathrm{N}_{\mathrm{c}}$.OS $\mathrm{M}_{1}, \mathrm{M}_{2}$ in $\chi$ such that $\mathrm{x}_{\mathrm{N}_{3}} \in \mathrm{M}_{1}, \mathrm{y}_{\mathrm{N}_{3}} \notin$ $M_{1}$ and $x_{N_{3}} \notin M_{2}, y_{N_{3}} \in M_{2}$. Therefore $(\chi, T)$ is not $N_{3} T_{1}$-space.

Then $(\chi, T) N_{3}$ semi $T_{1}$-space, But $(\chi, T)$ is not $N_{3} T_{1}$-space. Also $(\chi, T) N_{3}$ semi $T_{2}$-space, But $(\chi, T)$ is not $N_{3} T_{2}$-space.

\section{Theorem 3.14.}

Let $(\chi, \mathrm{T})$ be an $\mathrm{N}_{\mathrm{c}} \mathrm{TS}$, then :

1. Every $\mathrm{N}_{1} \mathrm{~T}_{2}$-space is $\mathrm{N}_{1}$ semiT $\mathrm{T}_{2}$-space.

2. Every $\mathrm{N}_{2} \mathrm{~T}_{2}$-space is $\mathrm{N}_{2}$ semiT $_{2}$-space.

3. Every $\mathrm{N}_{3} \mathrm{~T}_{2}$-space is $\mathrm{N}_{3}$ semiT $\mathrm{T}_{2}$-space.

\section{Proof:}

1. Suppose that $(\chi, T)$ is an $N_{1} T_{2}$-space, therefore for every two $x_{N_{1}} \neq y_{N_{1}}$, there exists an $N_{c} \cdot O S M_{1}, M_{2}$ in $\chi$ such that $\mathrm{x}_{\mathrm{N}_{1}} \in \mathrm{M}_{1}, \mathrm{y}_{\mathrm{N}_{1}} \notin \mathrm{M}_{1}$ and $\mathrm{x}_{\mathrm{N}_{1}} \notin \mathrm{M}_{2}, \mathrm{y}_{\mathrm{N}_{1}} \in \mathrm{M}_{2}$. with $\mathrm{M}_{1} \cap \mathrm{M}_{2}=\emptyset$. So there exists $\mathrm{N}_{\mathrm{c}} \mathrm{S}$.OS $\mathrm{M}_{1}, \mathrm{M}_{2}$ in $\chi$ such that $x_{N_{1}} \in M_{1}, y_{N_{1}} \notin M_{1}$ and $x_{N_{1}} \notin M_{2}, y_{N_{1}} \in M_{2}$. with $M_{1} \cap M_{2}=\emptyset$.

Therefore $\mathrm{X}$ is $\mathrm{N}_{1}$ semiT $\mathrm{T}_{2}$-space.

2. Similar to Proof 1 .

3. Similar to Proof 1.

\section{Remark 3.15.}

The converse of the Theorem 3.14 is not true, as it is shown in the following example.

\section{Example 3.16.}

Let $\chi=\{a, b, c\}, T=\left\{\emptyset_{N}, X_{N}, A, B, C\right\}, A=\{<\{a\}, \emptyset, \varnothing>\}, B=\{\langle\{b\}, \emptyset, \emptyset>\}, C=\{\langle\{a, b\}, \emptyset, \varnothing\rangle\}$. $N_{c} S . O S=\mathrm{T} \cup\{G=\{<\{a, c\}, \emptyset, \emptyset>\}, H=\{<\{b, c\}, \emptyset, \emptyset>\}$.

Let $\left.\mathrm{x}_{\mathrm{N}_{1}}=\{<\{b\}, \emptyset, \emptyset>\} \neq \mathrm{y}_{\mathrm{N}_{1}}=\{<\{c\}, \emptyset, \emptyset\rangle\right\} \in \chi$ there are no a $\mathrm{N}_{\mathrm{c}}$.OS $\mathrm{M}_{1}, \mathrm{M}_{2}$ in $\chi$ such that $\mathrm{x}_{\mathrm{N}_{1}} \in \mathrm{M}_{1}, \mathrm{y}_{\mathrm{N}_{1}} \notin$ $M_{1}$ and $x_{N_{1}} \notin M_{2}, y_{N_{1}} \in M_{2}$. Therefore $(\chi, T)$ is not $N_{1} T_{1}$-space.

Then $(\chi, T) N_{1}$ semi $T_{1}$-space, but $(\chi, T)$ is not $N_{1} T_{1}$-space. Also $(\chi, T) N_{1}$ semi $T_{2}$-space, but $(\chi, T)$ is not $N_{1} T_{2}$-space.

\section{Example 3.17.}

Let $\chi=\{a, b, c\}, \mathrm{T}=\left\{\emptyset_{N}, X_{N}, A, B, C\right\}, A=\{<\varnothing,\{a\}, \emptyset>\}, B=\{<\varnothing,\{b\}, \emptyset>\}, C=\{\langle\emptyset,\{a, b\}, \emptyset\rangle\}$. $N_{c} S . O S=\mathrm{T} \cup\{G=\{\langle\varnothing,\{a, c\}, \emptyset\rangle\}, H=\{\langle\emptyset,\{b, c\}, \emptyset\rangle\}$. 
Let $\mathrm{x}_{\mathrm{N}_{1}}=\{<\emptyset,\{b\}, \emptyset>\} \neq \mathrm{y}_{\mathrm{N}_{1}}=\{\varnothing,<\{c\}, \emptyset>\} \in \chi$ there are no $\mathrm{N}_{\mathrm{c}}$. OS $\mathrm{M}_{1}, \mathrm{M}_{2}$ in $\chi$ such that $\mathrm{x}_{\mathrm{N}_{2}} \in \mathrm{M}_{1}, \mathrm{y}_{\mathrm{N}_{2}} \notin$ $M_{1}$ and $x_{N_{2}} \notin M_{2}, y_{N_{2}} \in M_{2}$. Therefore $(\chi, T)$ is not $N_{2} T_{1}$-space.

Then $(\chi, T) \mathrm{N}_{2}$ semi $\mathrm{T}_{1}$-space, but $(\chi, \mathrm{T})$ is not $\mathrm{N}_{2} \mathrm{~T}_{1}$-space.

Also $(\chi, T) \mathrm{N}_{2}$ semiT 2 -space, but $(\chi, T)$ is not $\mathrm{N}_{2} \mathrm{~T}_{2}$-space.

Example 3.18.

Let $\left.\chi=\{a, b, c\}, \mathrm{T}=\left\{\emptyset_{N}, X_{N}, A, B, C\right\}, A=\{<\emptyset, \emptyset,\{a\}>\}, B=\{<\emptyset, \emptyset,\{b\}>\}, C=\{<\emptyset, \emptyset,\{a, b\}\rangle\right\}$.

$\left.N_{c} S . O S=\mathrm{T} \cup\{G=\{<\emptyset, \emptyset,\{a, c\}\rangle\}, H=\{<\emptyset, \emptyset,\{b, c\}\rangle\right\}$.

Let $\left.\left.\mathrm{x}_{\mathrm{N}_{3}}=\{<\varnothing, \emptyset,\{b\}\rangle\right\} \neq \mathrm{y}_{\mathrm{N}_{3}}=\{<\emptyset, \emptyset,\{c\}\rangle\right\} \in \chi$ there are no $\mathrm{N}_{\mathrm{c}}$.OS $\mathrm{M}_{1}, \mathrm{M}_{2}$ in $\chi$ such that $\mathrm{x}_{\mathrm{N}_{3}} \in \mathrm{M}_{1}, \mathrm{y}_{\mathrm{N}_{3}} \notin$ $M_{1}$ and $x_{N_{3}} \notin M_{2}, y_{N_{3}} \in M_{2}$. Therefore $(\chi, T)$ is not $N_{3} T_{1}$-space.

Then $(\chi, T) N_{3}$ semi $T_{1}$-space, But $(\chi, T)$ is not $N_{3} T_{1}$-space.

Also $(\chi, T) \mathrm{N}_{3}$ semi $\mathrm{T}_{2}$-space, $\operatorname{But}(\chi, \mathrm{T})$ is not $\mathrm{N}_{3} \mathrm{~T}_{2}$-space.

\section{Theorem 3.19.}

Let $(\chi, T)$ be an $\mathrm{N}_{\mathrm{c}} \mathrm{TS}$, then :

1. $\mathrm{N}_{1}$ semiT $_{2}$-space $\Rightarrow \mathrm{N}_{1}$ semiT $_{1}$-space $\Rightarrow \mathrm{N}_{1}$ semiT $_{0}$-space.

2. $\mathrm{N}_{2}$ semiT 2 -space $\Rightarrow \mathrm{N}_{2}$ semiT $_{1}$-space $\Rightarrow \mathrm{N}_{2}$ semiT 0 -space.

3. $\quad \mathrm{N}_{3}$ semiT - $_{2}$-space $\Rightarrow \mathrm{N}_{3}$ semiT 1 -space $\Rightarrow \mathrm{N}_{3}$ semiT $_{0}$-space.

The converse of the Theorem 3.19 is not true.

\section{Example 3.20.}

Let $X=\{a, b, c\}, S^{N C}=\left\{\emptyset_{N}, X_{N}, A\right\}, A=\{<\{a\}, \emptyset, \emptyset>\}$.

$N_{c} S . O S=\{A=\{<\{a\}, \emptyset, \emptyset>\}, C=\{<\{a, b\}, \emptyset, \emptyset>\}, B=\{<\{a, c\}, \emptyset, \emptyset>\}$.

Then $(\chi, \mathrm{T}) \quad \mathrm{N}_{1}$ semi $\mathrm{T}_{0}$-space, but $(\chi, \mathrm{T})$ is not $\mathrm{N}_{1}$ semi $\mathrm{T}_{1}$-space. So $(\chi, \mathrm{T}) \quad \mathrm{N}_{1}$ semi $\mathrm{T}_{0}$-space, But $(\chi, \mathrm{T})$ is not $\mathrm{N}_{1}$ semi $\mathrm{T}_{2}$-space.

\section{Remark. 3.21.}

Relations among the different types of neutrosophic crisp separation axioms which were studied in this paper, appear in the following diagram.

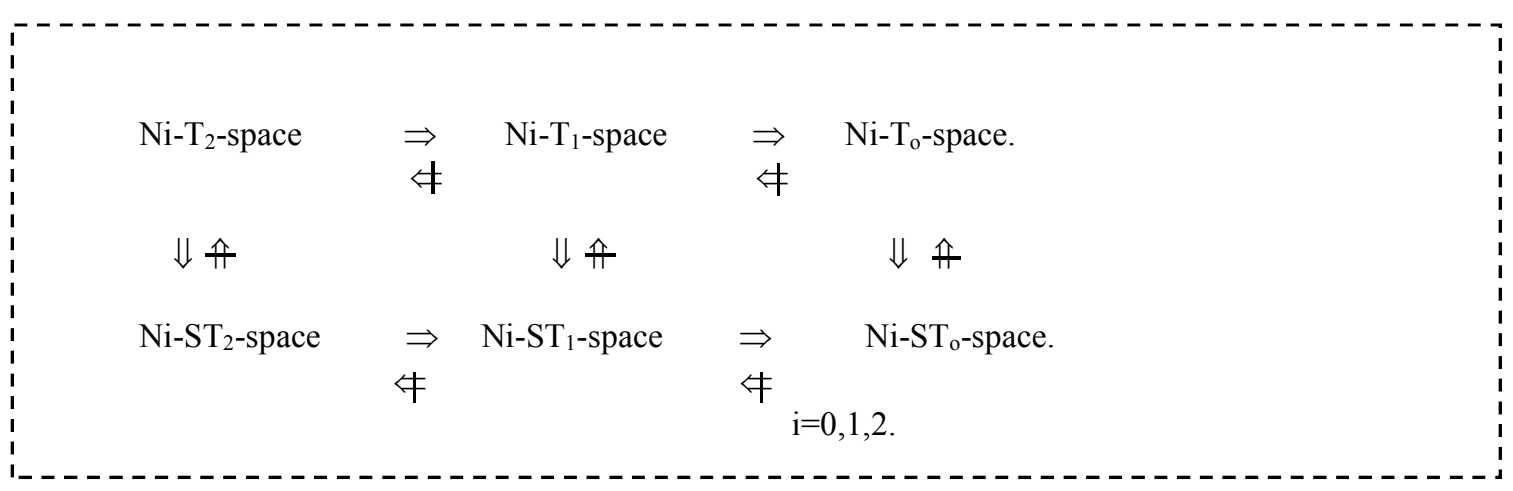

\section{Definition 3.22.}

An $\mathrm{N}_{\mathrm{c}} \mathrm{TS}(\chi, \mathrm{T})$ is called:

a. Nsemi $T_{0}$-space if $(\mathcal{X}, \mathcal{T})$ is $\mathrm{N}_{1}$ semi $\mathrm{T}_{0}$-space and $\mathrm{N}_{2}$ semi $\mathrm{T}_{0}$-space and $\mathrm{N}_{3}$ semi $\mathrm{T}_{0}$-space.

b. Nsemi $T_{1}$-space if $(\mathcal{X}, \mathcal{T})$ is $N_{1}$ semi $T_{1}$-space and $N_{2}$ semi $T_{1}$-space and $N_{3}$ semi $T_{1}$-space.

c. Nsemi $T_{2}$-space if $(\mathcal{X}, \mathcal{T})$ is $\mathrm{N}_{1}$ semi $\mathrm{T}_{2}$-space and $\mathrm{N}_{2}$ semi $\mathrm{T}_{2}$-space and $\mathrm{N}_{3}$ semi $\mathrm{T}_{2}$-space.

Remark3.23.

For an $\mathrm{N}_{\mathrm{c}} \mathrm{TS}(\chi, \mathrm{T})$

1. Every Nsemi $\mathrm{T}_{0}$-space if $(\mathcal{X}, \mathcal{T})$ is $\mathrm{N}_{1}$ semi $_{0}$-space. 
2. Every Nsemi $\mathrm{T}_{0}$-space if $(\mathcal{X}, \mathcal{T})$ is $\mathrm{N}_{2}$ semi $_{0}$-space.

3. Every Nsemi $\mathrm{T}_{0}$-space if $(\mathcal{X}, \mathcal{T})$ is $\mathrm{N}_{3}$ semi $\mathrm{T}_{0}$-space.

The converse is not true as it is shown in the below example.

Example 3.24.

Assume that $\mathrm{T}=\{\mathrm{x}, \mathrm{y}\}, \mathrm{T}_{1}=\left\{x_{\mathrm{N}}, \emptyset_{\mathrm{N}}, \mathrm{A}\right\}, \mathrm{T}_{2}=\left\{x_{\mathrm{N}}, \emptyset_{\mathrm{N}}, \mathrm{B}\right\}, \mathrm{T}_{3}=\left\{x_{\mathrm{N}}, \emptyset_{\mathrm{N}}, \mathrm{G}\right\}$.

$\mathrm{A}=<\{\mathrm{x}\}, \emptyset, \varnothing>$

$\mathrm{B}=<\emptyset,\{\mathrm{y}\}, \emptyset>$

$\mathrm{G}=<\varnothing, \varnothing,\{\mathrm{x}\}>$

Then: $(\chi, T)$ is $\mathrm{N}_{1}$ semi $\mathrm{T}_{0}$-space but not Nsemi $\mathrm{T}_{0}$-space.

$(\chi, T)$ is $\mathrm{N}_{2}$ semi $\mathrm{T}_{0}$-space but not $\mathrm{N}_{\text {semi }} \mathrm{T}_{0}$-space.

$(\chi, T)$ is $\mathrm{N}_{3}$ semi $\mathrm{T}_{0}$-space but not $\mathrm{N}_{\text {semi }} \mathrm{T}_{0}$-space.

Remark 3.25.

For an $\mathrm{N}_{\mathrm{c}} \mathrm{TS}(\chi, \mathrm{T})$

1. Every Nsemi $T_{1}$-space if $(\mathcal{X}, \mathcal{T})$ is $N_{1}$ semi $T_{1}$-space.

2. Every Nsemi $\mathrm{T}_{1}$-space if $(\mathcal{X}, \mathcal{T})$ is $\mathrm{N}_{2}$ semi $\mathrm{T}_{1}$-space.

3. Every $\mathrm{Nsemi}_{1}$-space if $(\mathcal{X}, \mathcal{T})$ is $\mathrm{N}_{3}$ semi $_{1}$-space.

The converse is not true as it is shown in the following example.

\section{Example 3.26.}

Assume that $=\{\mathrm{x}, \mathrm{y}\}, \mathcal{T}_{1}=\left\{\mathcal{X}_{\mathrm{N}}, \emptyset_{\mathrm{N}}, \mathrm{A}, \mathrm{B}\right\}, \mathcal{T}_{2}=\left\{\mathcal{X}_{\mathrm{N}}, \emptyset_{\mathrm{N}}, \mathrm{G}, \mathrm{F}\right\}$.

$\mathrm{A}=<\{\mathrm{x}\},\{\mathrm{y}\}, \emptyset>$

$\mathrm{B}=<\{\mathrm{y}\},\{\mathrm{x}\}, \emptyset>$

$\mathrm{G}=<\emptyset, \emptyset,\{\mathrm{x}\}>$

$\mathrm{F}=<\emptyset, \emptyset,\{\mathrm{y}\}>$

Then: $\left(\chi, T_{1}\right)$ is $N_{1}$ semi $T_{1}$-space but not Nsemi $T_{1}$.

$\left(\chi, T_{1}\right)$ is $\mathrm{N}_{2}$ semi $\mathrm{T}_{1}$-space but not Nsemi $\mathrm{T}_{1}$.

$\left(\chi, T_{2}\right)$ is $N_{3}$ semi $T_{1}$-space but not Nsemi $T_{1}$.

\section{Remark 3.27.}

For an $\mathrm{N}_{\mathrm{c}} \mathrm{TS}(\chi, \mathrm{T})$

1. Every $\mathrm{Nsemi}_{2}$-space if $(\mathcal{X}, \mathcal{T})$ is $\mathrm{N}_{1}$ semi $\mathrm{T}_{2}$-space.

2. Every Nsemi $\mathrm{T}_{2}$-space if $(\mathcal{X}, \mathcal{T})$ is $\mathrm{N}_{2}$ semi $\mathrm{T}_{2}$-space.

3. Every Nsemi $\mathrm{T}_{2}$-space if $(\mathcal{X}, \mathcal{T})$ is $\mathrm{N}_{3}$ semi $_{2}$-space.

The converse is not true as it is shown in the example.

\section{Remark 3.28.}

For an neutrosophic crisp topological space $(\mathcal{X}, \mathcal{T})$

1. Every Nsemi $\mathrm{T}_{1}$-space but not Nsemi $\mathrm{T}_{0}$-space.

2. Every Nsemi $\mathrm{T}_{2}$-space but not Nsemi $\mathrm{T}_{1}$-space.

The converse is not true as it is shown in the following example :

Example 3.29.

Assume that $=\{\mathrm{x}, \mathrm{y}\}, \mathcal{T}=\left\{\mathcal{X}_{\mathrm{N}}, \emptyset_{\mathrm{N}}, \mathrm{A}, \mathrm{B}, \mathrm{G}\right\}$.

$\mathrm{A}=<\{\mathrm{x}\}, \emptyset, \varnothing>$

$\mathrm{B}=<\emptyset,\{\mathrm{y}\}, \emptyset>$

$\mathrm{G}=<\emptyset, \emptyset,\{\mathrm{x}\}>$

Then: $(\mathcal{X}, \mathcal{T})$ is $\mathrm{Nsemi}_{0}$-space but not Nsemi $\mathrm{T}_{1}$-space.

\section{Conclusion}

In this paper, we have defined a new type of neutrosophic crisp separation axioms by using neutrosophic crisp semi open sets and certain point in the neutrosophic crisp topological spaces. Moreover,we study the connections between neutrosophic crisp semi separation axioms and the existing neutrosophic crisp separation axioms. And 
many examples are presented, to illustrate the concepts introduced in this paper. Also, investigate their fundamental properties and characterizations.

\section{References}

[1] A. A. Salama, F. Smarandache and Kroumov, "Neutrosophic crisp Sets and Neutrosophic crisp Topological Spaces" Neutrosophic Sets and Systems Vlo.2, pp.25-30, 2014.

[2] A. A. Salama, "Neutrosophic Crisp Points and Neutrosophic Crisp Ideals". Neutrosophic Sets and Systems 1, pp.50-54, 2013.

[3] A. A Salama, I. M Hanafy, Hewayda Elghawalby Dabash M.S, "Neutrosophic Crisp Closed Region and Neutrosophic Crisp Continuous Functions", New Trends in Neutrosophic Theory and Applications.

[4] A. A Salama, Hewayda Elghawalby,M.S. Dabash, A. M. NASR, "Retrac Neutrosophic Crisp System For Gray Scale Image", Asian Journal of Mathematics and Computer Research, Vol. 24, pp.104-117-22, 2018.

[5] A. A Salama, "Basic Structure of Some Classes of Neutrosophic Crisp Nearly Open Sets \& Possible Application to GIS Topology", Neutrosophic Sets and Systems, Vol. 7, pp.18-22, 2015.

[6] A. A Salama, F. Smarandache, "Neutrosophic Crisp Set Theory", Neutrosophic Sets and Systems, Vol. 5, pp.1-9, 2014.

[7] F. Smarandache, "Neutrosophy and Neutrosophic Logic, First International Conference on Neutrosophy, Neutrosophic Logic, Set, Probability, and Statistics" University of New Mexico, Gallup, NM 87301, USA 2002.

[8] M. Abdel-Basset, M. Mai, E. Mohamed, C. Francisco,H. Z. Abd El-Nasser, "Cosine similarity measures of bipolar neutrosophic set for diagnosis of bipolar disorder diseases" Artificial Intelligence in Medicine Vol. $101,101735,2019$.

[9] M. Abdel-Basset, E. Mohamed, G. Abduallah and F. Smarandache"A novel model for evaluation Hospital medical care systems based on plithogenic sets" Artificial intelligence in medicine 100 (2019), 101710.

[10] M. Abdel-Basset, G. Gunasekaran Mohamed, G. Abduallah. C. Victor, "A Novel Intelligent Medical Decision Support Model Based on Soft Computing and IoT" IEEE Internet of Things Journal, Vol. 7 ,2019.

[11] M. Abdel-Basset, G. Abduallah, G. Gunasekaran, L. Hoang Viet,"A novel group decision making model based on neutrosophic sets for heart disease diagnosis" Multimedia Tools and Applications, pp.1-26, 2019.

[12] A. B.AL-Nafeen R.K. Al-Hamido, F.Smarandache, "Separation Axioms In Neutrosophic Crisp Topological Spaces", Neutrosophic Sets and Systems, vol. 25, 25-32, 2019.

[13] F. Smarandache, S. Pramanik, "New Neutrosophic Sets via Neutrosophic Topological Spaces". In Neutrosophic Operational Research; Pons Editions: Brussels, Belgium, Vol. 1, pp.189-209, 2017.

[14] W. Al-Omeri, "Neutrosophic crisp sets via neutrosophic crisp topological spaces". Neutrosophic Sets Syst, Vol. 13, pp.96-104, 2016.

[15] W. Al-Omeri, S. Jafari "On Generalized Closed Sets and Generalized Pre-Closed Sets in Neutrosophic Topological Spaces", Mathematics, Vol. 7, pp.1-12, 2019. doi:doi.org/10.3390/math7010001.

[16] R.K. Al-Hamido, Q. H. Imran, K. A. Alghurabi, T. Gharibah, "On Neutrosophic Crisp Semi Alpha Closed Sets”, Neutrosophic Sets and Systems”, vol. 21, pp.28-35, 2018.

[17] Q. H. Imran, F. Smarandache, R.K. Al-Hamido, R. Dhavasselan, "On Neutrosophic Semi Alpha open Sets", Neutrosophic Sets and Systems, vol. 18, pp.37-42, 2017.

[18] R. K.Al-Hamido, “A study of multi-Topological Spaces”, PhD Theses, AlBaath university, Syria, 2019.

[19] R. K.Al-Hamido, "Neutrosophic Crisp Supra Bi-Topological Spaces", International Journal of Neutrosophic Science, Vol. 1, pp.66-73, 2018.

[20] R.K. Al-Hamido, "Neutrosophic Crisp Bi-Topological Spaces", Neutrosophic Sets and Systems, vol. 21, pp.66-73, 2018. 
[21] R.K. Al-Hamido, T. Gharibah, S. Jafari, F.Smarandache, "On Neutrosophic Crisp Topology via NTopology”, Neutrosophic Sets and Systems, vol. 21, pp.96-109, 2018.

[22] V. Christianto, F. Smarandache, M. Aslam, "How we can extend the standard deviation notion with neutrosophic interval and quadruple neutrosophic numbers", International Journal of Neutrosophic Science, vol. 2, No. 2, pp.72-76, 2020.

[23] E. O. Adeleke, A. A. A. Agboola, F. Smarandache, "Refined Neutrosophic Rings I ", International Journal of Neutrosophic Science, vol. 2 , No. 2, pp.77-81, 2020.

[24] E. O. Adeleke, A. A. A. Agboola, F. Smarandache, "Refined Neutrosophic Rings II", International Journal of Neutrosophic Science, vol 2 , No. 2, pp.89-94, 2020.

[25] M. A. Ibrahim, A. A. A. Agboola, E. O. Adeleke, S. A. Akinleye, "Introduction to Neutrosophic Subtraction Algebra and Neutrosophic Subtraction Semigroup", International Journal of Neutrosophic Science, vol. 2 , No. 1, pp.47-62, 2020.

[26] A. Hatip, “The Special Functions”, International Journal of Neutrosophic Science, vol. 4 , No. 2, pp.104$116,2020$. 